Third International Engineering Systems Symposium

CESUN 2012, Delft University of Technology, 18-20 June 2012

\title{
Design for safety: A new service for alarming and informing the population in case of emergency
}

\author{
H.M. Jagtman ${ }^{1}$ \\ ${ }^{1}$ Safety Science Group, Faculty of Technology Policy and Management. Delft University of \\ Technology. PO Box 50152600 GA DELFT, The Netherlands \\ h.m.jagtman@tudelft.nl
}

\begin{abstract}
In case of emergencies the population in danger should be alarmed so individuals can take action to get or remain out of danger. For alarming the population the means available are limited. Many countries have outdoor sirens. They operability however is limited since the siren has only one implicit instruction to the population. This instruction should moreover be known. The Safety Science Group has been involved in studying the potential effectiveness of alarming and informing the population via mobile phone messages since 2004 in national and EU context. In the course of 2012 this technology will come available for citizens' alarming in The Netherlands. This paper discusses the field of citizens' alarming and the type of technologies available to communicate to the population. This framework is relevant for understanding how one should asses a new technology from a safety point of view. One of the challenges for the new alarming service is the composition of a short message to alarm the population via their mobile phone, which is complete, relevant and correct for situation. This is new field which is recently being explored. We explain amongst others how the not yet known disaster is dominant for the message content and explain how a message can be composed. Results from workshop with experts from the emergency rescue services are discussed. We rounds off arguing dilemmas in order to get to effective citizens' alarming via the new service.
\end{abstract}

Keywords. cell broadcast, emergency warning system, alarm message content

\section{What is citizens' alarming?}

In case of a treat or incident governments have a responsible to alarm and inform the population (see bottom of Fig. 1). Alarming should notify the population in the affected area about the danger with the intention to change behaviour resulting in the population getting to a safe location or act safely in order to limit damage to people and properties. Notification of the population can be done either with or without special alarming technology. Many countries for this purpose have outdoor sirens (CHORIST SP3.D1 Deliverable, 2009) or make us of sound trucks or helicopters. The decision to notify the population via alarming technologies depends on the need to quicken the notification in order to limit damage. The population can also be warned without the need to speed up the notification. The means to notify people in such cases are for example the national or regional news, daily current affaire programs or newspapers. Informing is aimed at keeping the population who are or feel threatened updates about the situation. Informing different from alarming does not require (immediate) reaction for the population. The government informs the population via (regular) public meetings and via the media. Some examples of these channels used 
for citizens' alarming and their relation (see colour coding) to alarming and informing about the threat or the incident "A" are shown in the upper part of Fig. 1.

Not all technologies shown in Fig. 1are governmental controlled. Apart from the government also private parties and individuals communicate about a treat or incident. Current affairs programs decide themselves what they broadcast from official statements or public meetings. Moreover, the programs decide which persons (and experts) they invite to comment on the events. Also companies communicate in case of an incident to their own employees, visitors or customers. The population will also pass on a notification among themselves. Even for people-to-people communication various technologies are used. It could be passed on face-to-face, via telephone or internet to known and also unknown people. Finally certain threats are noticed by individuals in the vicinity or the source via their senses, for example via vision or smell.

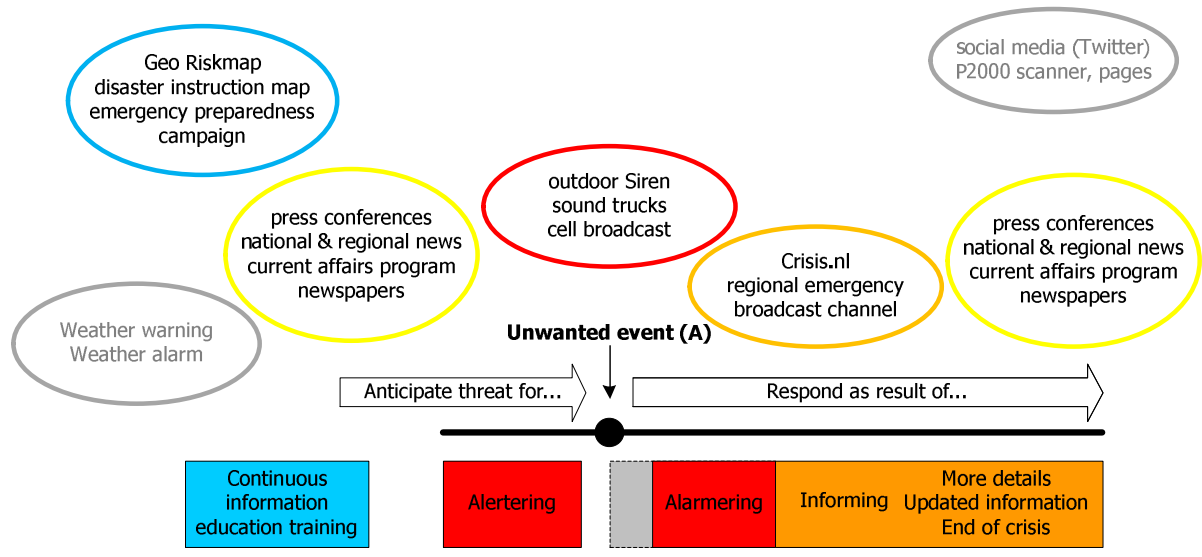

Fig. 1. Examples of channels for alarming and informing the population

\subsection{Risk versus disaster communication}

Alarming and informing relate to an incident. From emergency preparedness we also know communication about hazards. In this case it concerns risk communication which is aimed at educating the public about how they should respond if they will be in danger in some unknown future situation (see blue box in Fig. 1). Each Dutch municipality is obligated to instruct and prepare their residence for emergency cases. Secondly hazardous locations are shown to the public via a risk map.

\subsection{Problems with conventional alarming technologies}

Alarming technologies such as the outdoor siren system haven limitations due to design and operational specifications. In the Netherlands, for example, sirens can only be used if the required action is to go inside, shut doors and windows and turn off the ventilation system. This is the instruction about what do in case of the siren, which is educated to the population. This limited the type of threats and incidents for which use of sirens is an option. There are however other disaster scenarios for which other required actions could be relevant to communicate to the public. The population 
cannot be notified in any situation where one of these is the required action to get or stay safe. Such situations could be, for example, some explosion dangers, wildfires and certain floods or flood threats. Apart from limitations in the type of risks certain locations (especial rural locations) are not covered by outdoor sirens and hearingimpaired and deaf people will never be alarmed directly via the outdoor siren.

\subsection{Mobile phone technologies}

Meanwhile mobile phone technologies have become part of everyday life. Several private initiatives of safety and security services via mobile networks are available. Internationally known is Amber-Alert a service sending alerts in case of missing children. Examples in The Netherlands are: Burgernet; a service asking the population for information in safety or security related (police) problems via SMS which are sent to subscribers, SMS-Alert; which is similar to Burgernet. These services not only use SMS but also other new media platforms. All these services require subscription and sent message based on the zip code of the household. For citizens' alarming however message should be sent to people who are - at the moment of the incident - present in the area in danger. For every individual the area in danger is not necessarily one's place of residence. It could moreover be a location that one is visiting seldom. An alternative mobile phone technology which broadcast messages to a geographical area is cell broadcast (Samarajiva \& Waidyanatha, 2009). Cell broadcast will dispatch messages one-way, thus unconfirmed. Due to it functionality there is no guarantee that each mobile phone connected to the network in the area in danger will receive a message. This is not a necessity for effective alarming, however it should be known to anyone involved how this technology operates.

\section{Citizens' alarming via the mobile phone}

Fig. 2 shows the four processes which should function to be able to effectively alarm the population.

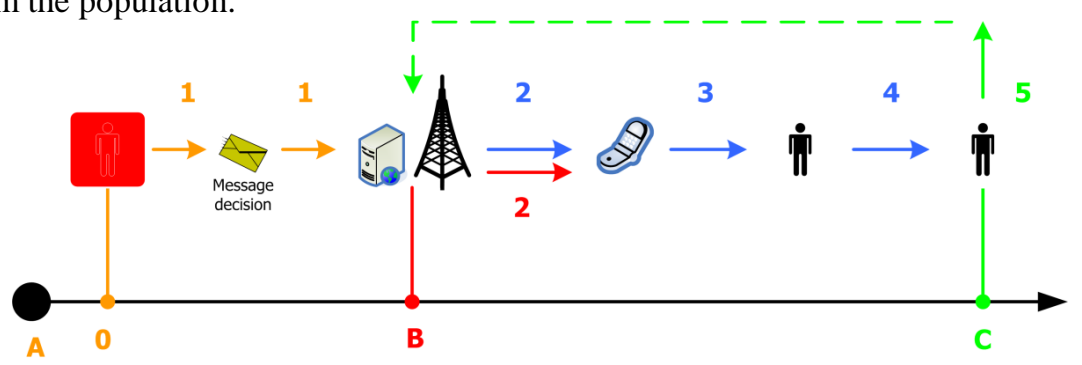

Fig. 2. Operation alarming chain when using mobile phone technology for citizens' alarm (Jagtman, Sillem, \& Wiersma, 2006)

The orange line shows the decision making of rescue services about the necessity of alarming the population, about the area to be warned and about the alarm text message. The red line shows the technological chain. The blue line showing the alarm message text which needs to be received on the mobile phone, needs to be notified, read and understood by the people. The green line finally shows the response of the 
population which should be in line with the action given in the alarm message text. Each of the four lines include different stakeholders how are responsible for correct functioning of their part in the alarm chain.

\subsection{NL-Alert: cell broadcast for citizens' alarming in The Netherlands}

Discussion about new technologies for public warning started over a decennium ago. The 1999 policy document on Disaster management (see Ministerie BZK, 1999) proposed to explore the possibilities of mobile phone technologies to warn the population. In 2005 and 2006 the first large-scale trials with population have taken place. The Safety Science Group has evaluated the public warning trials (CHORIST SP3.D55 Deliverable, 2008; Jagtman, 2010; Sillem, 2010). The evaluation included five themes: technology (understand the technological alarm chain from network to mobile phone), potential effectiveness (proportion of the respondents who were reached and responded properly to cell broadcast messages), message design (the content of alarming messages), acceptability (including user friendliness) and responsibility of stakeholders involved in the alarming chain. The evaluation of the trials showed that an alarming service using cell broadcast can function as long as all stakeholders involved acknowledge all linkages of the alarm chain (Jagtman, 2010). Important is not only to implement and control the technological chain, but also to set up a working procedure for emergency services (when and how to use NL-Alert) and citizens to create awareness about what is needed from them to be alarmed on their mobile phones.

In 2008 the Dutch government decided to introduce cell broadcast for citizens' alarming (Kamerstukken II 2007-2008, $29668 \mathrm{nr} 24$ ). The next step, in 2009, was to sign agreement with relevant partners for the availably of the technological infrastructure (orange and red lines in Fig. 2). These include all owners of mobile network in The Netherlands and in addition in intermediate stakeholder (a broker) between the operators and emergency rooms where a message will be created and dispatched. In 2010 the Parliament was informed about the progress of implementation of the service NL-Alert (Kamerstukken II 2009-2010, $29668 \mathrm{nr} 30$ ). Late 2011 it was announced that the system will be operable in stages starting from 2012 (Kamerstukken II 2010-2011, 29 668, nr 36).

Unique about the new Dutch alarm system, apart from the agreements with all involved Dutch mobile network owners, is that NL-Alert provides incident-related contextual alarm messages. Any NL-Alert will notify the population about the danger and in the same massage provide guides about the required action(s) to get or stay safe. An NL-Alert as such contributes to increasing emergency self-reliant behaviour of the population in danger (Sillem, 2010). This sets demands on defining the content of the alarm related to the incident for which it has to notify the population.

\subsection{Cell broadcast in other countries}

In multiple countries the use of cell broadcast to notify the population is considered. Most of these initiatives relate to early warnings for natural hazards. These often include mixture of different technologies to deliver a message to the population. Examples of such initiatives are shown in Table 1. 
Table 1. Example of mobile phone warning systems

\begin{tabular}{llll}
\hline Country & Aim of the service & Development stage & Reference \\
\hline Japan (Area mail) & & In use & nttdocomo \\
\hline $\begin{array}{l}\text { Sri Lanka (Disaster } \\
\text { and Emergency } \\
\text { Warning Network) }\end{array}$ & $\begin{array}{l}\text { first alert to emergency } \\
\text { personnel and public alerts } \\
\text { only when a threat is } \\
\text { adequately verified }\end{array}$ & $\begin{array}{l}\text { Launched in January } \\
\text { 2009 after testing }\end{array}$ & $\begin{array}{l}\text { Samarajiva \& } \\
\text { Waidyanatha } \\
(2009)\end{array}$ \\
\hline $\begin{array}{l}\text { Israel (National } \\
\text { Message) }\end{array}$ & $\begin{array}{l}\text { Earthquake and missile } \\
\text { warning }\end{array}$ & $\begin{array}{l}\text { demonstrated 2010 } \\
\text { civil defence drill } \\
\text { "Turning Point 4" }\end{array}$ & eVigilo \\
\hline $\begin{array}{l}\text { US (Emergency } \\
\text { Alert System) }\end{array}$ & $\begin{array}{l}\text { All hazard waring system } \\
\text { using various technologies }\end{array}$ & $\begin{array}{l}\text { In development and } \\
\text { testing }\end{array}$ & Moore (2010) \\
\hline
\end{tabular}

\section{A systems view on composing alarm messages}

Since NL-Alert aims to notify the population and simultaneously provide guidance for the required action, challenging apart from realizing the technological chain, is to be able to define the content of the alarm message related to an incident. In contrast to risk communication, in everyday non-emergency circumstances, the communicated preparation action(s) will not be sufficient for alarming about one specific incident. From these general messages "in case of an incident $\mathrm{X}$ do $\mathrm{Y}$ " the population cannot discover if incident type $\mathrm{X}$ is affecting them at that moment.

\subsection{System view on content of alarm messages}

The content of an alarm message depend on the type of incident, the moment of alarming or informing the population and the required action. For an alarm message the incident or more specific the hazard source is the starting point. Mileti \& Sorensen (1990) classify 14 different disaster types into three main sources: natural (geological or climatological), technology and social disasters. Countries prepare for various hazard sources which differ based on the chosen level of detail. Regarding natural disasters the classifications also differ because certain incidents, e.g. volcanic eruptions or tsunamis are not relevant for all countries (CHORIST SP3.D55 Deliverable, 2008).

The relation between type of incident, moment of alarming and action is shown in Fig. 3. Depending on the type of disaster certain moments to alarming will be more or less relevant. A tunnel fire, for example cannot be foreseen. An 'alert' message sent in case of a critical threat asking to precautionary measures as soon as possible to prevent getting affected in such cases in irrelevant. The relevant moments of alarming relates to the aim of a message: notify and alarm to limit personal losses or inform about the course of events. The incident circumstances and the moment of alarming determine relevant required actions to be communicated to the population. The incident circumstances include both the hazard source and the area which is potentially affected by this source. The alarming (and alerting) messages include first actions to be taken quickly to get or stay safe. 


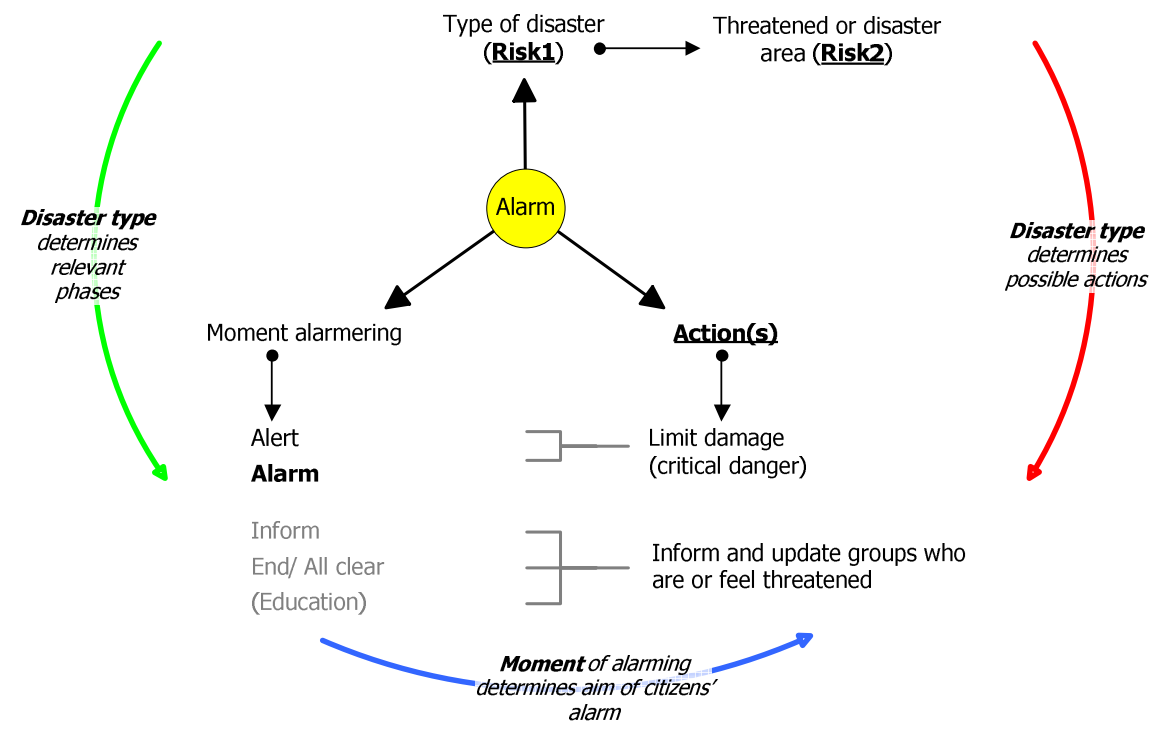

Fig. 3. Relationships between incident (disaster type), moment of alarm (type of message) and action (Jagtman, Sillem, \& Ale, 2011)

The informing messages may but not necessarily include a reminder to continue an action, such as keep windows closed, since the people in the area are still in danger. Depending on the functionality of the area in danger, the message should consider multiple different groups. If an incident has effect on an area around a city centre, the people present include for example residents of the neighbourhood and visitors. The latter could be frequent visitors such as people working, visiting schools and shopping in this area or infrequent visitors such as day trippers and tourists. These different people cannot necessarily undertake the same action. Since cell broadcast messages are geographically send, a message may need more than one action to serve different groups in the same area.

\subsection{Elements for alarming messages}

For alarming message, a web experiment in 2006 showed that these should include the components: Risk1 (the danger), Risk2 (the location in danger) and Action (CHORIST SP3.D55 Deliverable, 2008). Information about other media where more details can be found was less important and not necessary for a first alarming message. The experiences with receiving cell broadcast messages in 2005-2007 showed the need for additional information to be able to verify that a message indeed is an NL-Alert alarming message and to verify the relevance of the message at the moment of reading. For the later a time stamp in which the moment the message was sent by the rescue services would be helpful. These result in two more components: ID1 and ID2. All contextual components and the two identifiers can be related to the common alerting protocol CAP (CHORIST SP3.D55 Deliverable, 2008).

To define the content per component literature on emergency preparedness has been studied. The results are summarised in Table 2. For defining Risk1 we referred 
to the 18 Dutch disaster types. In some cases the danger itself is clear, in some cases however the origin should be added. For example if a toxic cloud is released from an industrial installation. To explore required actions risk communication plans from all Dutch safety regions have been analysed. This resulted in four categories of types of actions (see Table 2). The first three categories consist of concrete actions that people can take after reading. A fourth category, appeal to act self-reliant, does not provide guidance but rather ask take actions to get safe. Since risk communication is not related to one specific incident the component Risk2 is not covered.

Table 2. Identification and Content Elements (Jagtman, et al., 2011)

\begin{tabular}{|c|c|c|}
\hline Component & Elements & Importance \\
\hline ID1 & (NL-Alert) & Must \\
\hline \multirow{4}{*}{ Risk1 } & Danger & Must \\
\hline & Source of hazard & Depends on danger \\
\hline & Source location (stationary object) & Depends on source \\
\hline & Source location (transport object) & Depends on source \\
\hline \multirow{2}{*}{ Risk2 } & Name of village (toponym) & Must \\
\hline & Land marker & Option \\
\hline \multirow{4}{*}{ Action } & a) Geographical & \multirow{4}{*}{$\begin{array}{l}1 \text { action element is must } \\
\text { Which depends on the } \\
\text { incident (risk1) and the } \\
\text { location (risk2) }\end{array}$} \\
\hline & $\begin{array}{l}\text { b) do/don't actions after a geographical action } \\
\text { (e.g. shelter or stay away from falling objects) }\end{array}$ & \\
\hline & $\begin{array}{l}\text { c) do/don't actions without a geographical action } \\
\text { (e.g. use no drinking water, use paper tissues or } \\
\text { wash hands after contact) }\end{array}$ & \\
\hline & d) Appeal to act self-reliant & \\
\hline \multirow{2}{*}{ Info } & Other media & \multirow{2}{*}{ Option } \\
\hline & Access information (e.g., frequency) & \\
\hline ID2 & (date + time information) & Must \\
\hline
\end{tabular}

\subsection{Supporting rescue personnel to compose alarm messages}

Since the disaster type is dominant in determining the text for an alarm message a fixed and complete text cannot be defined beforehand. We can distinguish three approaches to compose a textual alarm message, which have little up to much freedom (Jagtman, et al., 2011): a - standardise approach (generic messages with empty text spaces), b - compare and adjust approach (example message which need modification for current incident) and c - activating and learning approach (use of test criteria to compose a message from 'blank'). The first approach requires a complete library of messages for any future incident, otherwise it will not be possible to select an appropriate message. In the second approach a library is necessary as well preferably as complete as possible. Since messages can be modified, a more or less similar danger and location can be found to use as inspiration for the message. However, in this approach tunnel vision cannot be ruled out. Especially if not the generally applicable action is required but an alternative action should be communicated. The last approach can cope with the variety and special circumstances which are linked to disasters and is therefore promising. It does require to educate and to train the rescue services to gain experience in composing short alarm messages to be sent to mobile phones. 
The system perspective (Fig. 3) shows an alarm text message can be considered useful for a specific threat or incident if the message is complete, relevant and correct for the situation (Jagtman, et al., 2011):

- An alarm message is complete if the receiver (the population) can determine what he or she should do to get or stay safe

- An alarm message is relevant if the receiver at the moment he or she reads the message can determine that the alarm is still relevant (valid) and that he or she belongs to the target group of the alarm

- An alarm message is correct for the situation if the receiver is urged to take action in accordance with the danger that is threatening him or her

For completeness the text in the alarm message should comply with the elements from Table 2. For relevance both identifiers should help as well as a clear description of the location (Risk2). The location description should be clear not only for daily present citizens but also for (infrequent) visitors. Correctness relates to the message that is composed and other messages that have or will be sent regarding the same incident. The message should not be counterproductive nor reduce self-reliant behaviour. The composed message should moreover not conflict with other messages, which among other things means that a new message is required if the situation changes. For each of these three test criteria a slide with rules is discussed in Jagtman, Sillem en Ale (2011).

\subsection{Alarm messages created by experts}

The test criteria have been used in a workshop in which three expert groups defined examples of alarm messages. The groups included a mixture of advisors from fire services, emergency centres, (crisis) communication specialists and behavioural specialists. During the workshop each team was first shown a short description of an emergency scenario. Based on this description a brainstorm was held to what should be included (or not) in an alarm message. This discussion let to a first version of an alarm message. That first version was subsequently tested using the criteria discussed in the previous section by the same group who had composed it. The testing resulted in a revised version of the alarm message. The revised alarm text message was shown to another expert team without the scenario description. This group was asked to discuss what they would do if they received this message. Secondly the scenario used to compose the message was revealed. The group is asked to review the alarm message text using the test criteria and if required propose a modified version of the alarm message.

The procedure of (a) writing a message, (b) testing and revising the message and (c) reviewing and revising by another group was done for 6 different scenarios. 14 experts participated in the workshop, who created in total 25 alarm messages. The review and revising step resulted in 7 messages, where analysed in detail. These messages were found to be complete and thus contain the required elements. 6 of the 7 messages however included more than the elements defined in Table 2. The "additional" pieces of texted statements which are common in risk communication, such as "think of others", "follow instruction of rescue services" and "limit the use of mobile phones". Analysing the relevance criteria it was found that some messages referred to one target group specifically which could confuse others. For example: 
"leave your car", what should you do if you are in the area but without a car? To emphasize the alarm character of the messages the experts had included words as "NOW" and "life threatening" in the text. The correctness of the messages was elaborated the most for alarm messages about heathland fires. After the review and revise step had a self-reliant component "leave the area; stay out of smoke", since it does not provide guidance in what direction people should leave.

Although the messages complied with the test criteria, they included more that required content. As a result the messages were quite long, which does not meet the desire of the population to receive short messages (CHORIST SP3.D55 Deliverable, 2008). In a recent experiment in which the population was asked to compose a message themselves it was found that the general people write shorter messages than the experts. The respondents moreover dislike the "additional" components originating from risk communication in the messages composed by experts (Jagtman, Sillem, \& Ale, 2012).

\section{Discussion: issues to realise an effective new alarming service}

As the relationships in Fig. 3 showed composing an alarm message does not stand on its own. In the round up of this paper we discuss four dilemmas which play a role in realizing an effective alarming system in practice. There are more dilemmas, for example relating to the characteristics of the technology, which make it impossible to monitor how many individuals spread over the area in danger are actually alarmed.

Dilemma I: stakeholder's responsibilities versus effective alarming of the population in danger. The technology cell broadcast can only be effective if all the linkages from the alarm chain shown in Fig. 2 are functioning. To realise this at the moment of an incident, the emergency services should decide to alarm and compose a message which the mobile networks should be functioning. In addition citizens, who are present in the area in danger, should have their mobile phone active and their phones should be noticeable to them. Subsequently, after notifying an alarm, people should read it, understand it and respond in accordance to the guidance given in the message. Although the mobile operators cannot be held responsible for the content of the message nor for the response to the message, they should acknowledge that the effectiveness of an alarm message is not only to reach as many people as possible, but also to have the relevant people respond to a message. They should consider their role in building expectations of what their customers (whom are part of the population that may need to be warned) should do in order to be able to receive a message.

Dilemma II: emergency preparedness versus emergency response. All the research related to cell broadcast for citizens' alarming was undertaken in non-emergency circumstances, since there is no system yet. This not only related to the trials in which cell broadcast messages have been sent, but also the investigation into the content of alarm messages. As was shown in the experiment with experts, they put items related to the main goals of risk communication in a message for disaster communication. The effect of adding these 'additional' elements is not known. It may reduce the distinguishing characteristics of alarming messages. Even though the population in various experiments have stated this to be annoying and sometimes patronising, it is not clear if that will affect a response if people are really in danger. A question about 
the importance of the various message components showed different answers in a questionnaire about a big industrial fire in The Netherlands that another experiment about citizens' alarming messages for fires and explosions. In that questionnaire the importance of explaining the danger (Risk1) was a lot higher, this component will help to determine relevance for the current moment (Jagtman, et al., 2012).

Dilemma III: alarming and notification via the same technology. In this paper the service to alarm the population was leading to discuss how cell broadcast can be used (see positioning of cell broadcast in Fig. 1). However, from a technological point of view cell broadcast can be used both to alarm and to inform the population about an incident. As shown in Fig. 1 many channels are available to do the latter. Citizens can however not be informed or updated about a situation before being notified. Alarming requires persuasion of reader to stop what he or she is doing and act in accordance to the message (green arrow in Fig. 2). Credibility of a sender influences compliance with the instruction in a message (Baron, Byrne, \& Johnson, 1998; Williams \& Noyes, 2007; Wogalter, Dejoy, \& Laughery, 1999). A sender is considered trustful if its communication has no conflicts of interest. Potentially alarming and information messages can have conflicts. For example, when for a first incident an information message is received for which no action is required, while for a later other incident an alarm message is received which requires immediate action. Receiving multiple informative messages could decrease the urgency for an alarming message via the same communication channel.

Dilemma IV: First to alarm versus confirmation unauthorised information. Since the trial period 2005-07 the use of social media networks increased significantly. People search at almost any place for information. In crisis communication this has shifted from the authorities will tell you what is going on to thinking in terms of a mix of means which includes both traditional media (radio, tv and newspapers) and new media (internet, social media). Most of these channels however are useful for informing but not for alarming. Since an individual will not notice something is posted on the internet if you are busy with another activity. New media have another problem. While traditional media are often criticised about being late with information, new media have shown to be inaccessible due to network overload in several disaster situations. Another problem is the trustworthiness of social media information. Walters (2011) argues he followed the news about the a Dutch shooting via Twitter. When verifying all he had read he found that Twitter had informed him quicker but all he had learned was found to be false information about the event. A second example occurred when a national broadcast channel had posted "Beatrix Hersenbloeding" (Dutch Queen brain haemorrhage) unintentionally on Twitter instead of searching with these words ("Leve de koningin, met dank aan Shownieuws," 2011). The post was retweeted quickly by multiple followers and many other media subsequently paid attention to this non-news (van den Breemer \& Lindhout, 2011). These examples show that the government will most likely not be the first to announce. This has also never been the intention. The potential of increasing amount of false information could increase the need to confirm or disprove unauthorised information. 


\section{References}

Baron, R. A., Byrne, D., \& Johnson, B. T. (1998). Exploring Social Psycholgy (4 ed.). Needham Heights, MA: Allyn and Bacon.

CHORIST SP3.D1 Deliverable. (2009). Meta definition and general categorisation for citizens early warning messages. Delft: TU Delft.

CHORIST SP3.D55 Deliverable. (2008). Lessons learned by Delft University of Technology on Emergency Warnings. Delft: TU Delft.

eVigilo. IDF Home Command. Retrieved 5 April 2012, from http://www.evigilo.net/

Jagtman, H. M. (2010). Cell broadcast trials in The Netherlands: Using mobile phone technology for citizens' alarming. Reliability Engineering \& System Safety, 95(1), 18-28.

Jagtman, H. M., Sillem, S., \& Ale, B. J. M. (2011). Bouwstenen voor alarmberichten in het kader van NL-Alert. Rapportage over de ontwikkeling van berichtgeving voor burgeralarmering via cell broadcast. Delft: TU Delft.

Jagtman, H. M., Sillem, S., \& Ale, B. J. M. (2012). NL-Alert: na welk alarmbericht komt u in actie? Resultaten van een webbased experiment waarin de bevolking helpt effectieve berichten voor burgeralarmering te ontwikkelen. Delft: TU Delft.

Jagtman, H. M., Sillem, S., \& Wiersma, J. W. F. (2006). Implementation issues on citizens alarming using mobile phone technology. Paper presented at the International Conference on Probabilistic Safety Assessment and Management (PSAM8), New Orleans.

Leve de koningin, met dank aan Shownieuws. (2011, 19-11-2011). NRC.

Mileti, D. S., \& Sorensen, J. H. (1990). Communication of emergency public warnings: A social science perspective and state-of-the-art assessment. Washington, DC: Federal Emergency Management Agency.

Ministerie van BZK. (1999). Beleidsnota Rampenbestrijding 2000-2004. Den Haag.

Moore, L. K. (2010). The Emergency Alert System (EAS) and All-Hazard Warnings (Vol. RL32527). Washington D.C.: Congressional Research Service.

NTT Docomo. Chapter 9: Early warning area mail. Retrieved 5 April 2012, from http:// www.nttdocomo.co.jp/english/binary/pdf/support/trouble/manual/network/area_mail.pdf

Samarajiva, R., \& Waidyanatha, N. (2009). Two complementary mobile technologies for disaster warning. The journal of policy, regulation and strategy for telecommunications, information and media, 11(2), 58-65.

Sillem, S. (2010). Warning citizens; Influencing self-reliance in an emergency. TU Delft.

van den Breemer, A., \& Lindhout, S. (2011). De 'Zieke Grap' van LuckyTV \& de Brieven van boycot Bram, Volkskrant.

Walters, D. (2011, 12-04-2011). Twitter wint op snelheid maar faalt als nieuwsbron, NRC $\cdot$ Next.

Williams, D. J., \& Noyes, J. M. (2007). How does our perception of risk influence decisionmaking? Implications for the design of risk information. Theoretical Issues in Ergonomic Science, 8(1), 1-35.

Wogalter, M. S., Dejoy, D. M., \& Laughery, K. R. (Eds.). (1999). Warnings and Risk Communication (1 ed. Vol. 1). London: Taylor \& Francis Ltd. 